\title{
Cerebral Blood Flow during Acute Acidosis in Perinatal Goats
}

\author{
RICHARD L. BUCCIARELLI AND DONALD V. EITZMAN \\ Division of Neonatology, Depariment of Pediatrics, University of Florida College of Medicine, Gainesville,
} Florida, USA

\begin{abstract}
Summary
Changes in cerebral blood now in response to three states of acute acidosis, posthypoxic, lactic acid, and respiratory, were estimated by the microsphere technique. In all three states, the fraction of the systemic blood flow reaching the brain and the rate ( $\mathrm{ml} / \mathrm{min}$ ) of blood now to it increased. The increase in flow was linearly related both to the $\mathrm{PaCO}_{2}$ and to $\mathrm{H}^{+}$. Others have shown the now rate to increase with hypercapnia, but the increase associated with an increase in hydrogen ion concentration while the $\mathrm{PaCO}_{2}$ was maintained at control levels does not appear to have been observed in mature animals.
\end{abstract}

\section{Speculation}

The significant increase in cerebral blood flow seen in perinatal goats during acute acidosis seems to be a result of a decrease in cerebral vascular resistance in an attempt by the cerebral vascular bed to preserve flow to the brain during stress.

Acute acidosis, metabolic and respiratory, is frequently encountered in the care of sick infants. Premature infants with hyaline membrane disease often exhibit hypercapnia secondary to respiratory failure and a metabolic acidosis secondary to a combination of hypoxemia and poor tissue perfusion with consequent lactic acidosis (II). Currently, the leading cause of perinatal morbidity and mortality in acidotic premature infants with hyaline membrane disease is intraventricular bleeding (12). With these facts in mind, we have studied the response of the cerebral vascular bed in perinatal and neonatal goats when acute acidosis is induced.

\section{MATERIALS AND METHODS}

Of the 41 kids studied, 21 were between 130 and 148 days of gestation (term 148-152 days) and 20 were between 1 and 34 days old. All were under light chloralose anesthesia $(70 \mathrm{mg} / \mathrm{kg})$. The fetuses were delivered by Cesarean section with the umbilical circulation intact; after cannulation of the trachea they were ventilated by means of a pump. Once an inflation pressure of 15-20 $\mathrm{cm} \mathrm{H}_{2} \mathrm{O}$ had been established, the cord was clamped. The neonates were ventilated in the same manner with peak inspiratory pressures of $15-20 \mathrm{~cm} \mathrm{H} \mathrm{H}_{2} \mathrm{O}$ without any expiratory pressure.

To introduce catheters in the left atrium and main pulmonary artery, a left thoracotomy was performed, either on the third or fourth intercostal space. A silastic catheter borne on a 22-gauge needle was inserted into the pulmonary artery and one of polyethylene into the atrium through an incision in its appendage. Both were secured with purse string sutures. A catheter in a femoral artery served to follow the aortic pressure. The catheters were connected to Statham transducers and the pressures recorded on a direct writing polygraph. Core temperature, monitored with a rectal probe, was maintained between $37^{\circ}$ and $38^{\circ}$ with an infrared lamp and an electric heating pad. The mean systemic pressure was 55-60 Torr during all experiments.

The preparation completed, base line values for the mean systemic and pulmonary arterial pressures, arterial blood gases, hematocrit, and serum solids were determined. The animal was then allowed to stabilize for at least $10 \mathrm{~min}$. It was then made acidotic by one of the three methods described below, and while in that state the cerebral blood flow and the distribution of systemic blood flow were determined by the microsphere technique. The acidotic state was then corrected either by a change in ventilation or the administration of sodium bicarbonate $(0.88$ $\mathrm{mEq} / \mathrm{ml}$ ). Cerebral blood flow was determined again in the corrected state.

Each animal was observed during two different acidotic states and two corrected states. The order was randomized.

The acidotic states were produced as follows: Posthypoxic acidosis was produced by ventilating the preparation with nitrogen until the heart rate fell to $50 / \mathrm{min}$ and/or the systolic pressure in the aorta had fallen to $\mathbf{4 0}$ Torr or less. The animal was then returned to oxygen. The $\mathrm{PaCO}_{2}$ was controlled at $40 \pm 2.1$ Torr. Lactic acidosis was produced by the infusion of a solution of lactic acid at a rate of $1 \mathrm{mEq} \mathrm{kg} / / \mathrm{min}$ for $5-10 \mathrm{~min}$. During lactic acidosis the $\mathrm{PaCO}_{2}$ was controlled at $41 \pm 1.6$ Torr. Respiratory acidosis was induced by increasing the ventilator dead space.

The ratio of brain blood flow and the distribution of the systemic blood flow were evaluated by injecting an appropriate dose of carbonized microspheres $(15 \pm 5 \mu$ in diameter and labeled with either ${ }^{855} \mathrm{Sr},{ }^{5 i} \mathrm{Cr},{ }^{141} \mathrm{Ce}$, or ${ }^{169} \mathrm{Yb}$ ) into the left atrium while blood was withdrawn from the abdominal aorta at a constant rate of $7.5 \mathrm{ml} / \mathrm{min}$ for I $\mathrm{min}$. This sample was subsequently counted and used as a reference to calculate organ flow. We have accepted the suggestions of Buckberg et al. (3) and have made injections of the microspheres into the left atrium in an attempt to ensure complete mixing with blood before being injected into the systemic circuit, hopefully reducing errors resulting from nonuniform ejection of spheres from the left ventricle. In addition, a sufficient quantity of spheres was injected to ensure at least 400 spheres to each major organ again to eliminate errors in calculations due to uneven distribution of spheres before being ejected into the systemic circuit (3). Before and after the microsphere injection, samples for blood gas analysis were drawn from the pulmonary artery, left atrium, and femoral artery. Hemalocrit and serum solids were monitored and kept in normal ranges throughout the experiment.

At the end of the experiment the animal was killed. The viscera, including the brain, were removed. The eviscerated body, head, and neck were considered a unit and referred to collectively as the "carcass." Each organ was ashed and counted separately. Counts for the different isotopes were separated according to the methods of Rudolph and Heymann (8). Organ blood flow was calculated by relating the count from each organ to the count in the reference sample from the aorta obtained at a known flow rate (count $\cdot 7.5$ $\mathrm{ml}^{-1} / \mathrm{min}$ ). Systemic blood flow was calculated as the sum of the organ flows. 
Table 1. Experimental conditions ${ }^{1}$

\begin{tabular}{|c|c|c|c|c|c|c|c|c|}
\hline & pH & $\begin{array}{l}\mathrm{PaCO}_{2} \\
\text { (Torr) }\end{array}$ & $\begin{array}{r}\mathrm{PaO}_{2} \\
\text { (Torr) } \\
\end{array}$ & $\begin{array}{c}\text { Base } \\
\text { excess }\end{array}$ & $\begin{array}{c}\text { FA } \\
(\mathrm{mm} H \mathrm{Hg})\end{array}$ & $\begin{array}{c}\mathrm{PA} \\
(\mathrm{mm} \mathrm{Hg})\end{array}$ & $\begin{array}{l}\mathrm{Hct} \\
(\%)\end{array}$ & $\begin{array}{c}\text { Serum solids } \\
(\mathrm{mg} / \mathrm{dl})\end{array}$ \\
\hline Control & $7.42 \pm 0.005$ & $40 \pm 1.4$ & $250 \pm 13.1$ & $-2.2 \pm 0.3$ & $56 \pm 2.8$ & $27 \pm 3.0$ & $32.8 \pm 3.0$ & $4.0 \pm 0.5$ \\
\hline Respiratory acidosis & $7.12 \pm 0.03$ & $70 \pm 4.4$ & $170 \pm 10.5$ & $-6 \pm 1.1$ & $52 \pm 3.6$ & $30 \pm 4.5$ & $29.9 \pm 2.2$ & $4.5 \pm 0.5$ \\
\hline Posthypoxic acidosis & $7.22 \pm 0.05$ & $40 \pm 2.1$ & $224 \pm 22$ & $-10.9 \pm 0.7$ & $49 \pm 7.0$ & $34 \pm 3.1$ & $33.7 \pm 2$ & $3.9 \pm 0.3$ \\
\hline
\end{tabular}

' Values are mean $\pm \mathrm{SE}$.

Table 2. Mean percentage of change in regional blood flow and systemic blood flow with acute acidosis in perinatal goats

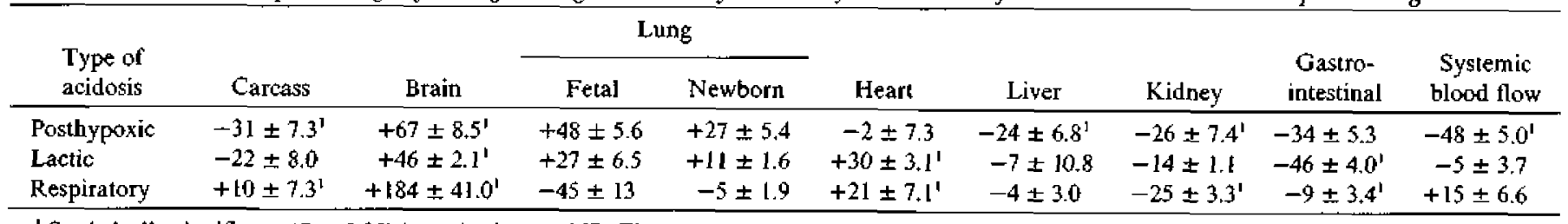

' Statistically significant $(P \leq 0.05)$ by paired $l$ test. NB: Figures are mean percentages of change in flow \pm SE.

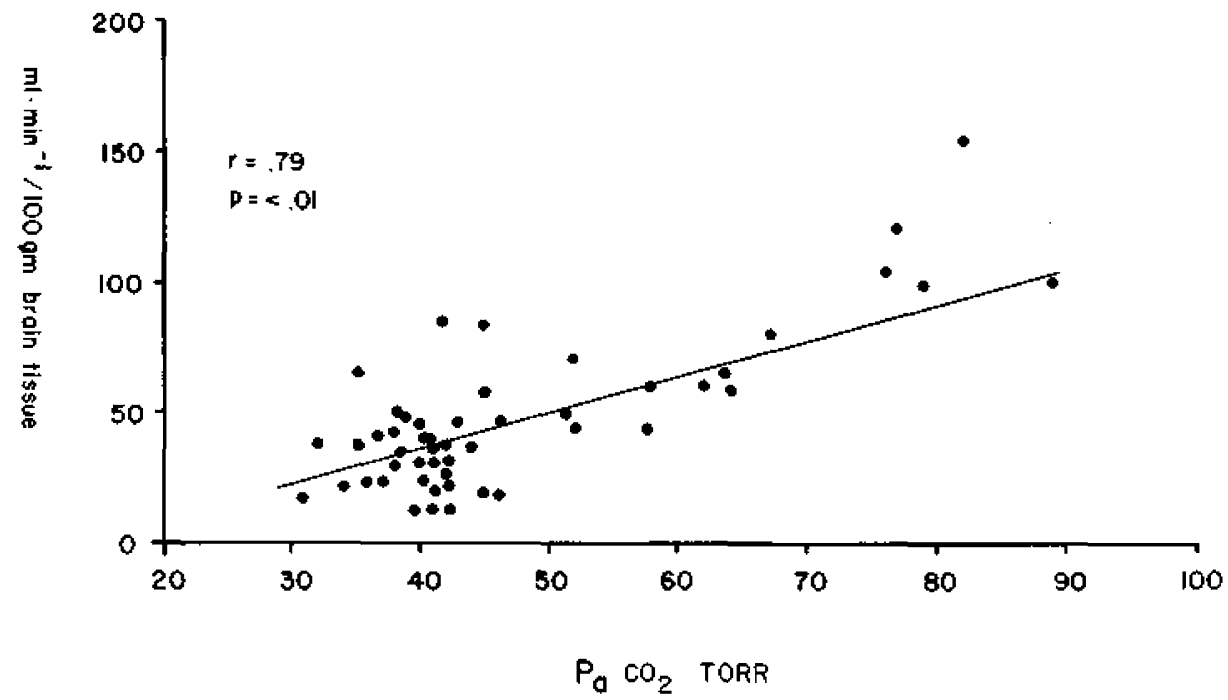

Fig. I. Cerebral blood flow as a function of $\mathrm{PaCO}_{2}: \mathrm{PaCO}_{2}$ in Torr appears on ordinate. Cerebral blood flow (m]- $\mathrm{min}^{-1} / 100 \mathrm{~g}$ brain tissue) atong abscissa. Line drawn from linear regression analysis of data, $r=0.79$.

\section{RESULTS}

The mean value for blood gases, mean systemic artery pressure, mean pulmonary artery pressure, hematocrit, and serum solid for each experimental condition are listed in Table I. There was no significant difference between mean systemic artery pressures, mean pulmonary artery pressure, hematocric, or serum solids in any of the groups.

Table 2 lists the mean percentage of change in organ blood flow during the acidotic state. There was a uniform increase in cerebral blood flow with all types of acidosis. The largest increase occurred with respiratory acidosis where cerebral blood flow almost tripled (mean increase of $184 \%$ of control values). Cerebral blood flow also increased by $67 \%$ over control values in the posthypoxic state, despite a drop in systemic blood flow to approximately one-half the control values $(48 \%)$.

Changes in actual cerebral blood flow (ml. $\mathrm{min}^{-1} / 100 \mathrm{~g}$ brain tissue) in response to changes in $\mathrm{PaCO}_{2}$ and hydrogen ion concentration were analyzed and pictorially presented in Figures 1 and 2 . Figure 1 shows a linear relation between $\mathrm{PaCO}_{2}$ and cerebral blood flow ( $r=0.79$ by linear regression analysis). Similarly, during posthypoxia and lactic acidosis, when $\mathrm{PaCO}_{2}$ was constant $(40 \pm 2.1$ Torr and $41 \pm 1.6$ Torr, respectively), cerebral blood flow was also linearly related to hydrogen ion concentration (Fig. 2), although less closely than to $\mathrm{PaCO}_{2}(r=0.64$ by linear regression analysis).

\section{DISCUSSION}

The response of the cerebral vascular bed of a fetus and a mature animal during acute hypercapnia and/or acute hypoxemia has been extensively studied $(1,4,5,7,9,10)$. Increases in arterial tension of carbon dioxide have been shown to produce a dramatic increase in cerebral blood flow $(1,9)$. This vasodilatory effect has been thought by some to be due to a direct action of carbon dioxide on the smooth muscle of cerebral vessels (10).

Eitzman et al. (4) have shown an increase in the carotid blood flow of newborn goats during acute ventilation with $6 \%$ oxygen. The animals were hyperventilated during the experiment, resulting in a normal pH (mean 7.39). Carotid blood flow promptly returned to control values when the animal was returned to room air (4). Similarly, Rudolph (7) has shown an increase in fetal cerebral blood flow when the fetus was made hypoxemic by inducing maternal hypotension. Here, hypoxemia was accompanied by a mixed metabolic and respiratory acidosis (7).

The effect of hydrogen ion concentration on cerebral blood flow is less well documented. Shieve and Wilson (9) have reported, in adult humans, a $25 \%$ reduction in cerebral blood flow with the infusion of an $0.8 \mathrm{NH}_{4} \mathrm{Cl}$ solution. Furthermore, Lambertsen et al. (6) observed that in the absence of hypoxia, hydrogen ion has little effect on cerebral blood flow in adult animals.

In our experiments, cerebral blood flow increased, as expected, during hypercapnia with a mean increase of $184 \%$ over those of 